\title{
Freezing Injury and Rheological Properties of Agricultural Products
}

\author{
Shigehiko OHNISHI, ${ }^{1}$ Tomoyuki FUJII ${ }^{2}$ and Osato MIYAWAKI ${ }^{3}$ \\ ${ }^{1}$ Fermentation and Food Research Institute, Kagawa Prefectural Industrial Technology Center, 1351-1 Noma, Uchinomi, Kagawa 761-4421, \\ Japan \\ ${ }^{2}$ Faculty of Applied Life Sciences, Niigata University of Pharmacy and Applied Life Sciences, 265-1 Higashijima, Niitsu, Niigata 956-8603, \\ Japan \\ ${ }^{3}$ Department of Applied Biological Chemistry, The University of Tokyo, 1-1-1 Yayoi, Bunkyo-ku, Tokyo 113-8657, Japan
}

Received May 16, 2003; Accepted September 2, 2003

\begin{abstract}
Time changes in electrical and rheological properties of carrot and potato cell tissues after freezing-thawing or chloroform-vapor treatment were compared to clarify the mechanism of cell tissue softening by freezing injury. Integrity of cell plasma membrane was analyzed by the electrical measurement and rheological properties of cell tissues were determined by the vibrating reed method. Changes in the rheological properties by the chloroform-vapor treatment were assumed to be caused only by the loss of turgor pressure, while those by the freezing-thawing were caused by loss of this pressure and injuries to the cell wall and intercellular structure. The change in the rheological properties of carrot and potato tissue by the freezing-thawing and chloroform-vapor treatment were compared to determine the contribution ratio of the loss of turgor pressure and injuries to the cell wall and intercellular structure, which are known as major causes of softening by freezing injury. Findings showed that the loss of turgor pressure due to plasma membrane injury is the main reason for cell tissue softening by freezing injury while injuries to the cell wall and intercellular structure have an auxiliary role.
\end{abstract}

Keywords: freezing injury, impedance, carrot, potato, cell plasma membrane, cell wall, turgor pressure

Freezing has been known to lead to deterioration in the quality of agricultural products, which generally cause undesirable enzymatic reactions and result in softening of cell tissues, browning, and degradation of nutritional components. Many investigations on freezing of agricultural products have been focused on changes in the nutritional components, while little attention has been paid to date to rheological properties.

The rheological properties of agricultural products reflect turgor pressure (Virgin, 1955), which is very sensitive to the state of plasma membrane in the cell tissue. The plasma membrane is considered to be the primary site of freezing injury because of its weak structure (Burke et al., 1976; Steponkus, 1984; Webb et al., 1994; Dejmek \& Miyawaki, 2002). In addition, the state of cell wall also is known to affect the rheological properties of agricultural products during the freezing process. However, contributions of the changes in plasma membrane and the cell wall to cell tissue softening have not been evaluated separately because freezing injury takes place simultaneously in these two places.

The plasma membrane, which consists of a lipid bilayer, is thought to be independently injured in the contact with chloroform. This reaction is probably useful to evaluate the effect of freezing injury in the membrane on the rheological properties of agricultural products. In the present study, changes in electrical and rheological properties of carrot and potato cell tissues before and after freezing-thawing were compared with those after chloroform-vapor treatment. Changes in rheological properties of cell tissues and integrity of plasma membrane during the treatments were then analyzed to elucidate the mechanism of cell tissue

E-mail: ohnishi@itc.pref.kagawa.jp softening by freezing injury.

\section{Materials and Methods}

Reagent All chemicals used were of reagent grade and obtained from Nacalai Tesque, Inc. (Kyoto).

Biological materials Carrot (Daucus carota L.) root and potato (Solanum tuberosum $\mathrm{L}$.) tuber were obtained from a local market, and cylindrical samples $(6.9 \mathrm{~mm}$ in diameter, $50 \mathrm{~mm}$ in length) were prepared with a cork borer ( $6.9 \mathrm{~mm}$ inner diameter) for electrical and rheological measurements.

Freezing-thawing treatment Cylindrical samples were wrapped with Parafilm (American National Can, USA) to prevent drying and left in a refrigerator at $5^{\circ} \mathrm{C}$ for $30 \mathrm{~min}$, then cooled and frozen in a domestic freezer at $-18^{\circ} \mathrm{C}$. The temperature was measured by a copper-constantan thermocouple at the center of each sample. After freezing, samples were thawed for 1 $\mathrm{h}$ at room temperature $\left(25^{\circ} \mathrm{C}\right)$ until their temperature reached approximately $20^{\circ} \mathrm{C}$.

Chloroform-vapor treatment A $50 \mathrm{ml}$-beaker with $30 \mathrm{ml}$ of chloroform and a $50 \mathrm{ml}$-beaker with $30 \mathrm{ml}$ of deionized water were placed in a 1000 ml-beaker. The 1000 ml-beaker was capped by a sheet of aluminum foil and left at room temperature $\left(25^{\circ} \mathrm{C}\right)$ for one night so that the atmosphere was saturated with chloroform-vapor. A petri dish with a sample was put into the 1000 ml-beaker and was left for an arbitrary period of time (Fig. 1).

Measurement of impedance Integrity of the plasma membrane was analyzed by an electrical measurement (Ishikawa et al., 1997; Ohnishi et al., 2002). The electrical properties of agricultural products were measured by a LCR meter (3523-50; Hio- 


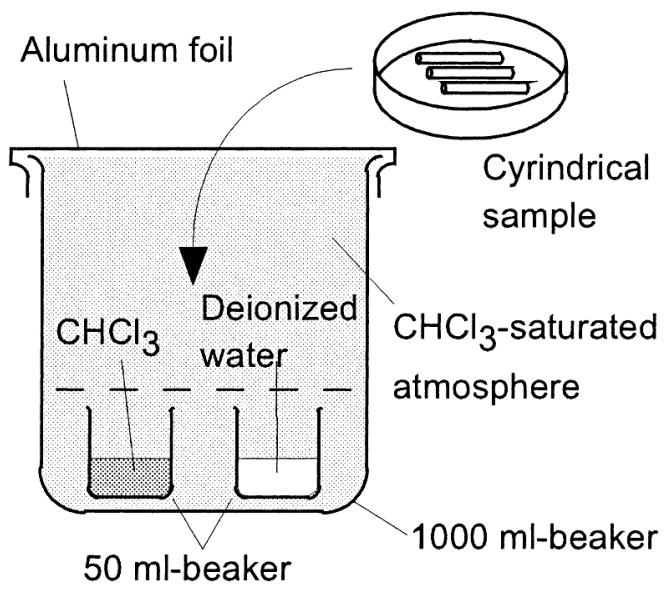

Fig. 1. Schematic diagram of experimental apparatus for chloroform-vapor treatment.

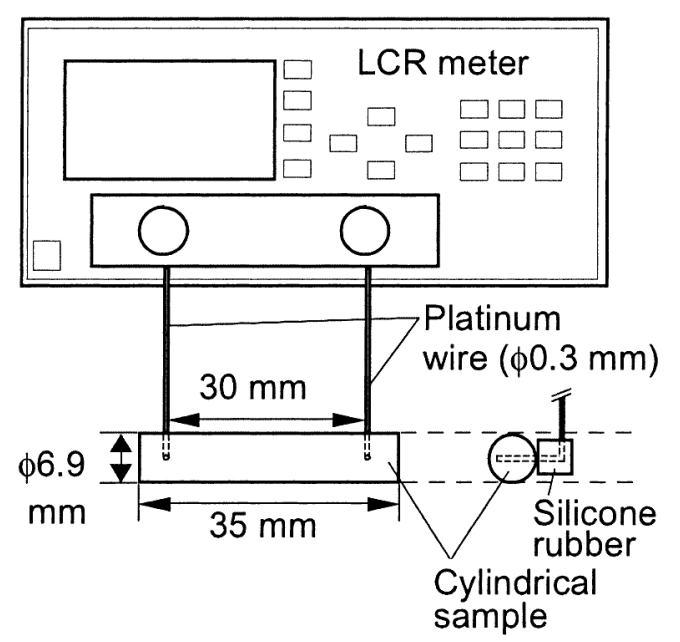

Fig. 2. Schematic diagram of experimental apparatus for measurement of impedance by a LCR meter.

ki, Japan) with a test fixture (16047C; Hewlett-Packard Japan). Two electrodes of platinum wire $(0.3 \mathrm{~mm}$ in diameter $)$ connected to the test fixture were plunged into a sample ( $5 \mathrm{~mm}$ deep) in the direction perpendicular to the long axis of the cylindrical sample $(6.9 \mathrm{~mm}$ in diameter, $35 \mathrm{~mm}$ in length) as shown in Fig. 2. The distance between the two electrodes was $30 \mathrm{~mm}$. Impedance of the sample was measured over a frequency range from $50 \mathrm{~Hz}$ to $1 \mathrm{MHz}$ at 0.1 volt. Three different samples were used at a fixed condition and the mean impedance value was obtained.

Measurement of rheological properties Rheological properties of agricultural products were determined by the vibrating reed method (Dejmek \& Miyawaki, 2002; Ohnishi et al., 2002; Drake, 1962; Miyawaki \& Yano, 1980). The experimental apparatus for measurement by this method is shown in Fig. 3. Cylindrical samples were dipped in liquid paraffin (Nacalai Tesque, Inc.) to prevent drying during measurement. The top end of the cylindrical beam sample $(6.9 \mathrm{~mm}$ in diameter, $35-45 \mathrm{~mm}$ in length) was held by a sample holder of acrylic resin, and vibrated at a frequency varied from 0 to $100 \mathrm{~Hz}$ by an electromagnetic vibrator (Model PET-0A; IMV Corporation, Japan). The move-

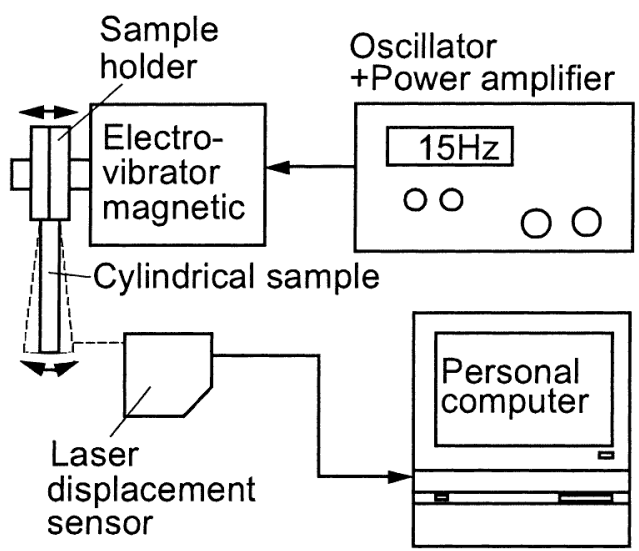

Fig. 3. Schematic diagram of experimental apparatus for measurement of rheological properties by vibrating reed method.

ment of the bottom edge as a free end of the beam was measured by a laser displacement sensor (LK-030; Keyence Corporation, Japan), and the resonance curve was analyzed. Dynamic elasticity $\left(E^{\prime}\left[\mathrm{N} / \mathrm{m}^{2}\right]\right)$ and dynamic viscosity $\left(\eta^{\prime}\left[\mathrm{N} \cdot \mathrm{s} / \mathrm{m}^{2}\right]\right)$ were calculated from the following equations (Nishinari et al., 1977).

$$
\begin{gathered}
E^{\prime}=\rho \frac{4 \pi^{2} l^{4}}{a_{0}{ }^{4} k^{2}} f^{2}\left\{1-\left(\frac{3}{8}\right)\left(\frac{\Delta f}{f}\right)^{2}\right\}, \\
\eta^{\prime}=\rho \frac{2(4) \pi l^{4}}{a_{0}{ }^{4} k^{2}} \Delta f\left\{1-\left(\frac{3}{8}\right)\left(\frac{\Delta f}{f}\right)^{2}\right\},
\end{gathered}
$$

where $f[\mathrm{~Hz}]$ is the resonance frequency, $\Delta f[\mathrm{~Hz}]$ is the width of the resonance curve at which the resonance amplitude is $1 / \sqrt{2}$ times the maximum resonance amplitude, $l[\mathrm{~cm}]$ is the length of the beam sample excluding the part held by the sample holder, $D$ $[\mathrm{cm}]$ is the diameter of the sample, $\rho\left[\mathrm{g} / \mathrm{cm}^{3}\right]$ is the density of the sample, $a_{0}$ is a constant for the fundamental vibration (1.875), and $k^{2}$ is the moment of inertia of the cross section around the neutral axis per cross section area $\left(D^{2} / 16\right.$ for cylindrical sample). At a fixed condition of freezing-thawing and the chloroformvapor treatment, measurements were repeated three times for different samples to obtain the dynamic viscoelasticity. Density of a sample was measured with an electric density meter (EW200SG; Mirage Trading, Inc., Osaka) that measures the sample weights in air and in water. A mean density value from three samples was used for calculating viscoelasticity using Eqs. (1) and (2).

\section{Results and Discussion}

Change in electrical and rheological properties by freezingthawing Figures 4 and 5 show changes in impedance $\left(\mathrm{Z}_{100 \mathrm{kHz}}\right)$ and rheological properties of carrot and potato cell tissue samples with time in the freezing process at $-18^{\circ} \mathrm{C}$. The impedance after freezing-thawing decreased with an increase in freezing period, showing an increase in the plasma membrane injury by ice crystal formation (Ohnishi et al., 2002). The impedance decreased rapidly after ca. 20 and $30 \mathrm{~min}$ both for carrot and potato when the temperatures attained a range between -3 and $-5^{\circ} \mathrm{C}$. This temperature range corresponds to the lower limit of the zone of maximum ice crystal formation where most free water in the cell tissue changes to ice. Thus, the plasma membrane would have 
sustained serious injury caused by the volume increment in the formation of ice crystals. The dynamic elasticity and viscosity of cell tissue after freezing-thawing decreased with a decrease in the impedance. These results show that intactness of the plasma membrane plays an important role in determining the viscoelasticity of cell tissue. From these data, the loss of turgor pressure due to plasma membrane injury is thought to be the major reason for the change in rheological properties of agricultural products after freezing-thawing (Burke et al., 1976; Steponkus, 1984; Webb et al., 1994; Dejmek \& Miyawaki, 2002).

Chloroform-vapor treatment of cell tissue Figures 6 and 7

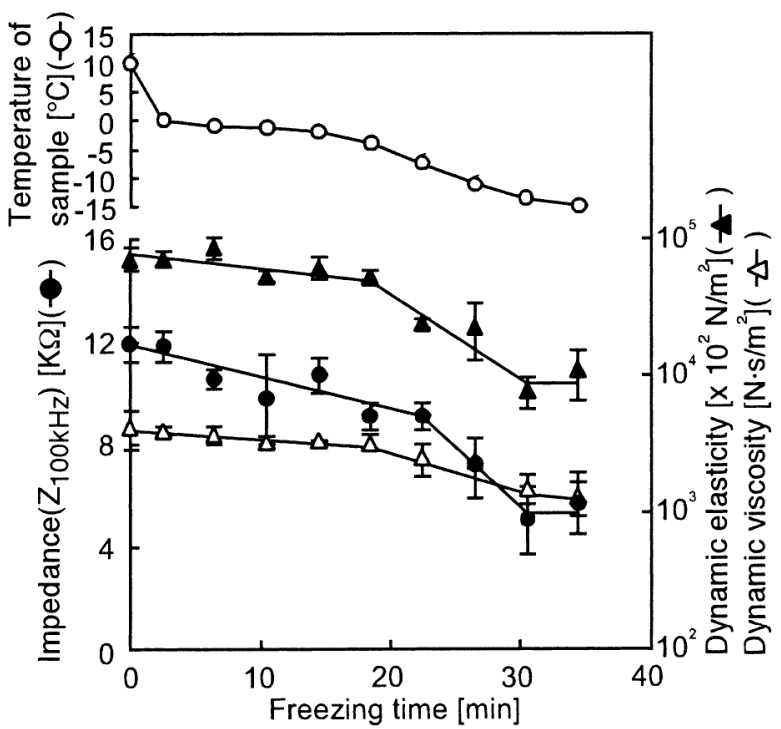

Fig. 4. Changes in impedance, dynamic elasticity and dynamic viscosity during the freezing-thawing process of carrot tissue sample at $-18^{\circ} \mathrm{C}$. $\mathbf{0}$, impedance; $\bigcirc$, temperature of sample; $\boldsymbol{\Delta}$, dynamic elasticity; $\Delta$ dynamic viscosity.

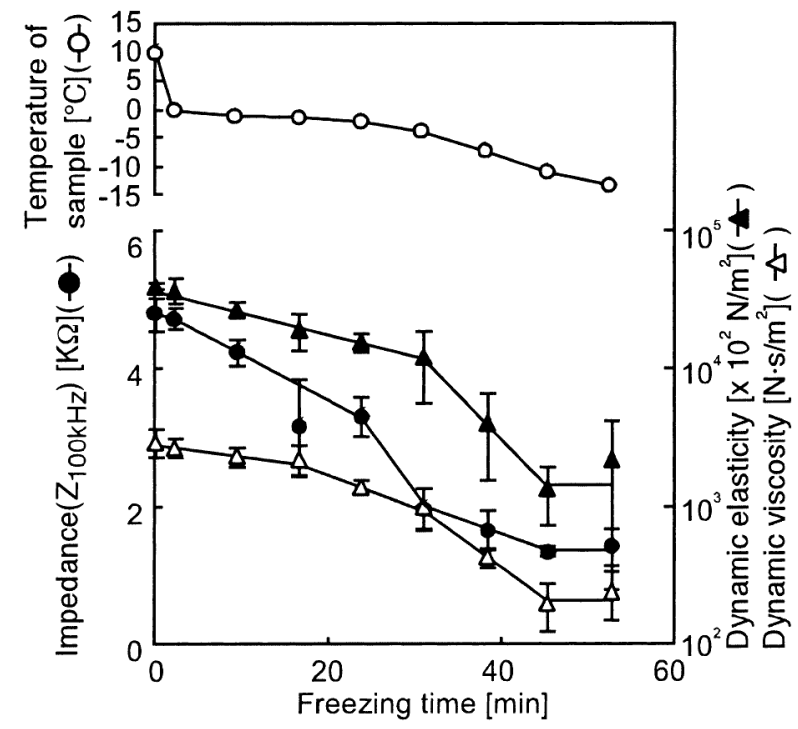

Fig. 5. Changes in impedance, dynamic elasticity and dynamic viscosity during the freezing-thawing process of potato tissue sample at $-18^{\circ} \mathrm{C}$. $\mathbf{O}$, impedance; $\bigcirc$, temperature of sample; $\boldsymbol{\Delta}$, dynamic elasticity; $\triangle$, dynamic viscosity. show changes in impedance and rheological properties of carrot and potato cell tissue samples with time in the chloroform-vapor treatment. The impedance of cell tissues decreased with increase in the treatment time, indicating that this treatment, as well as freezing-thawing, changes the structure of the plasma membrane. In freezing-thawing, the plasma membrane was physically broken by the formation of ice crystals, while in the chloroformvapor treatment the plasma membrane was thought to be injured chemically. In animal cells it is known that the toxicity of chloroform to cells at a high dose is mainly due to a solvent effect (Råbergh \& Lipsky, 1997). Although little is known about the effect of chloroform on the plasma membrane of plant cells, the lipid bilayer structure of this membrane might be broken by the solvent effect of chloroform similar to that in animal cells. Chloroform dissolved slightly in water (solubility $0.8 \mathrm{wt} \%$ ). When cell tissue is left in the saturated chloroform-vapor, the chloroform gradually dissolves into the cytoplasm. Chloroform in the cytoplasm is immediately taken up by the lipid bilayer of plasma membrane and finally the structure of the bilayer might be bro-

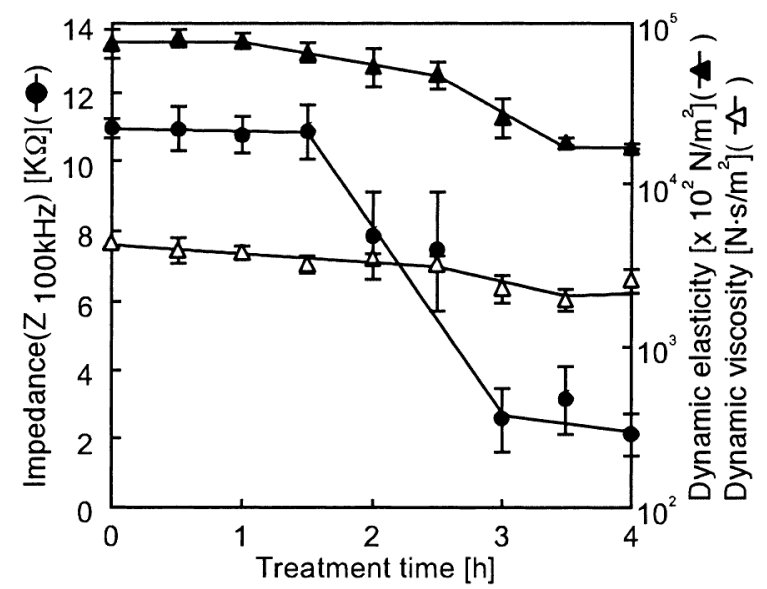

Fig. 6. Changes in impedance, dynamic elasticity and dynamic viscosity during the chloroform-vapor treatment of carrot tissue sample. $\boldsymbol{O}$, impedance; $\boldsymbol{\Lambda}$, dynamic elasticity; $\triangle$, dynamic viscosity.

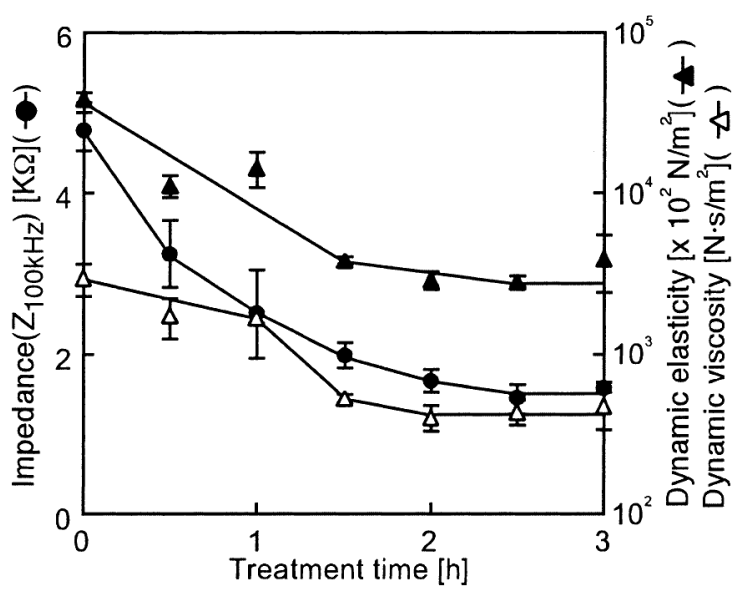

Fig. 7. Changes in impedance, dynamic elasticity and dynamic viscosity during the chloroform-vapor treatment of potato tissue sample. $\boldsymbol{Q}$, impedance; $\boldsymbol{\Delta}$, dynamic elasticity; $\triangle$, dynamic viscosity. 
Table 1. Change in impedance and rheological properties of cell tissues before and after freezing-thawing or chloroform-vapor treatment.

\begin{tabular}{|c|c|c|c|c|}
\hline & \multicolumn{2}{|c|}{ Carrot } & \multicolumn{2}{|c|}{ Potato } \\
\hline & Elasticity $\left[10^{6} \mathrm{~N} / \mathrm{m}^{2}\right]$ & Viscosity $\left[10^{3} \mathrm{~N} / \mathrm{m}^{2}\right]$ & Elasticity $\left[10^{6} \mathrm{~N} / \mathrm{m}^{2}\right]$ & Viscosity $\left[10^{3} \mathrm{~N} / \mathrm{m}^{2}\right]$ \\
\hline Fresh $(\mathrm{A})^{a)}$ & $7.25 \pm 1.39$ & $4.23 \pm 1.32$ & $3.96 \pm 0.24$ & $2.95 \pm 0.68$ \\
\hline After freezing-thawing treatment $(\mathrm{B})^{b)}$ & $0.93 \pm 0.37$ & $1.40 \pm 0.32$ & $0.18 \pm 0.14$ & $0.22 \pm 0.08$ \\
\hline After chloroform-vapor treatment $(\mathrm{C})^{c)}$ & $1.79 \pm 0.08$ & $2.28 \pm 0.38$ & $0.34 \pm 0.08$ & $0.44 \pm 0.11$ \\
\hline$(\mathrm{A})-(\mathrm{B})^{d)}$ & 6.32 & 2.83 & 3.78 & 2.73 \\
\hline$(\mathrm{A})-(\mathrm{C})^{e)}$ & $5.46(86.4)^{g)}$ & $1.95(68.9)^{g)}$ & $3.62(95.8)^{g)}$ & $2.51(91.9)^{g)}$ \\
\hline$(\mathrm{C})-(\mathrm{B})^{f)}$ & $0.86(13.6)^{g)}$ & $0.88(31.1)^{g)}$ & $0.16(4.2)^{g)}$ & $0.22(8.1)^{g)}$ \\
\hline Crude fiber $[\%]$ & \multicolumn{2}{|c|}{1.0} & \multicolumn{2}{|c|}{0.4} \\
\hline
\end{tabular}

${ }^{a)}$ Each value is mean \pm S.E. for 3 samples.

${ }^{b)}$ Each value is mean \pm S.E. for 6 samples (carrot, 31 and $35 \mathrm{~min}$; potato, 46 and $53 \mathrm{~min}$ ).

c) Each value is mean \pm S.E. for 6 samples (carrot, 3.5 and $4.0 \mathrm{~h}$; potato, 2.5 and $3.0 \mathrm{~h}$ ).

${ }^{d)}$ Total decrease in viscoelasticity during freezing and thawing at $-18^{\circ} \mathrm{C}$.

${ }^{e)}$ Decrease in viscoelasticity due to loss of cell turgor pressure by chloroform-vapor treatment.

${ }^{f)}$ Decrease in viscoelasticity due to change in properties of cell wall and intercellular structure by freezing-thawing.

${ }^{g)}$ Percentage of total decrease in viscoelasticity by freezing-thawing at $-18^{\circ} \mathrm{C}$.
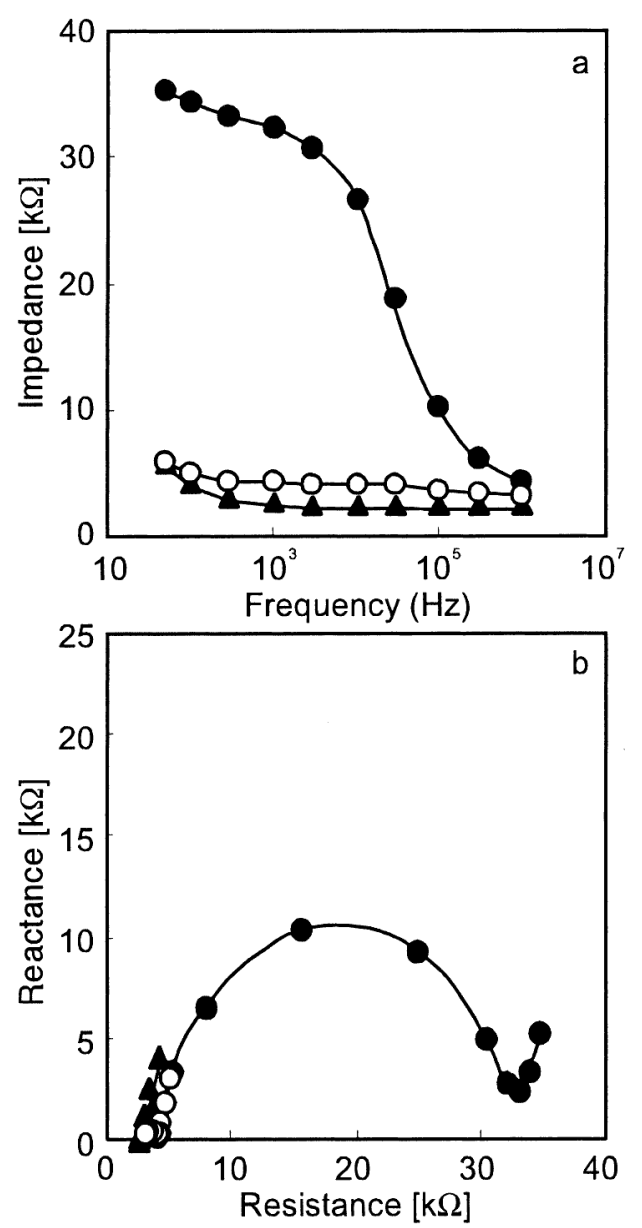

Fig. 8. Electrical properties of carrot tissue sample before and after freezing-thawing or chloroform-vapor treatment. $\bigcirc$, fresh sample; $\bigcirc$, after freezing-thawing at $-18^{\circ} \mathrm{C}$ for $35 \mathrm{~min}$; $\boldsymbol{\Delta}$, after the chloroform-vapor treatment for $4 \mathrm{~h}$.

ken by the solvent effect of the chloroform. Therefore, the dynamic elasticity and viscosity of cell tissues decreases with a decrease in the impedance after the chloroform-vapor treatment as well as the freezing-thawing. In the former treatment, however, the viscoelasticities observed are somehow different from those after freezing-thawing as shown in Table 1. This difference may reflect the different mechanism for the injury between these two
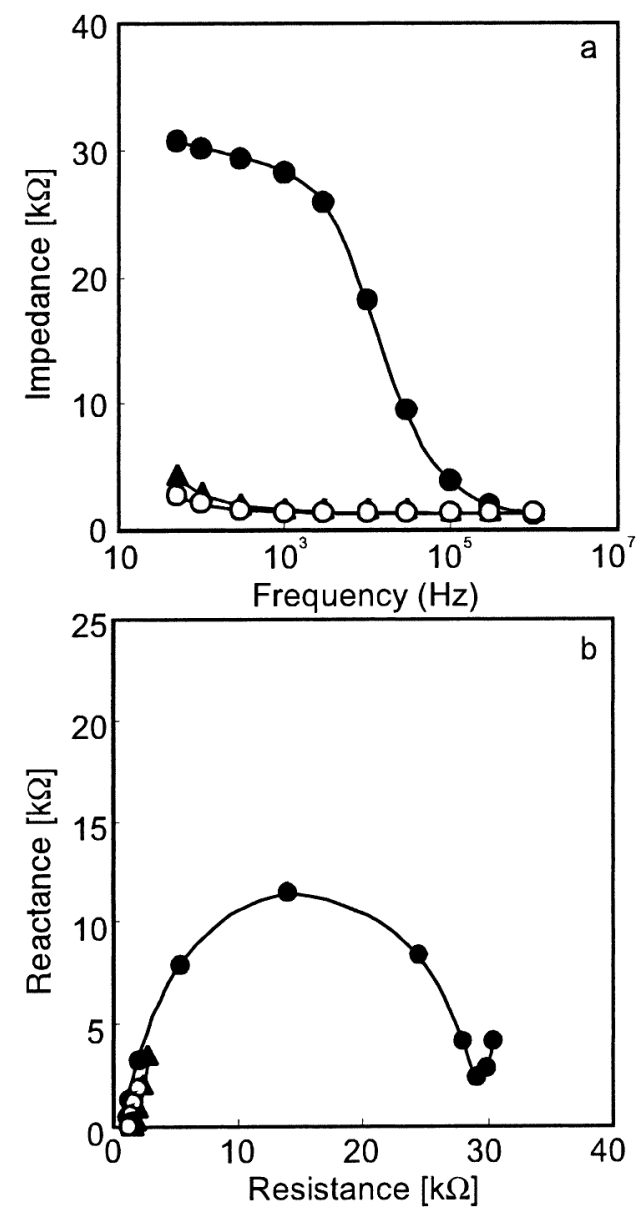

Fig. 9. Electrical properties of potato tissue sample before and after freezing-thawing or chloroform-vapor treatment. $\mathbf{O}$, fresh sample; $\bigcirc$, after freezing-thawing at $-18^{\circ} \mathrm{C}$ for $53 \mathrm{~min} ; \boldsymbol{\Delta}$, after the chloroform-vapor treatment for $3 \mathrm{~h}$.

treatments.

Comparison of freezing-thawing and chloroform-vapor treatment Electrical properties were analyzed further to compare the state of the plasma membrane after the freezing-thawing and the chloroform-vapor treatment. Impedance of a carrot tissue sample was measured over a frequency range from $50 \mathrm{~Hz}$ to 1 $\mathrm{MHz}$ at 0.1 volt (Fig. 8a). In a fresh carrot tissue, a very clear 
dependence on frequency was observed in the impedance. This frequency dependence in impedance ( $\beta_{1}$ dispersion) shows that the cell tissue structure is composed of the aggregation of closed cell spaces separated by the plasma membrane (Toyoda et al., 1997; Sugiyama, 1988). After the freezing-thawing or the chloroform-vapor treatment, no frequency dependence was observed showing that the plasma membrane was injured by these treatments and the confinement of the cell structure was lost. To confirm this, reactance and resistance of a carrot tissue were measured over a frequency range from $50 \mathrm{~Hz}$ to $1 \mathrm{MHz}$ to obtain the Cole-Cole plot (Cole, 1932) shown in Fig. 8b. For a fresh carrot tissue sample, the characteristic arc was clearly observed in the Cole-Cole plot showing the existence of the closed cell structure separated by the plasma membrane. This arc completely disappeared after the freezing-thawing or the chloroform-vapor treatment. This drastic change in the Cole-Cole plot suggests that the plasma membrane was seriously injured after these treatments (Dejmek \& Miyawaki, 2002). A similar result was also observed for potato tissue samples (Fig. 9, a and b).

Changes in the viscoelasticity of cell samples after the freezing-thawing and chloroform-vapor treatment were compared. In the freezing-thawing of carrot tissue, the initial elasticity $(7.25 \times$ $\left.10^{6} \mathrm{~N} / \mathrm{m}^{2}\right)$ and viscosity $\left(4.23 \times 10^{3} \mathrm{~N} \cdot \mathrm{s} / \mathrm{m}^{2}\right)$ finally decreased to $0.93 \times 10^{6} \mathrm{~N} / \mathrm{m}^{2}$ and $1.40 \times 10^{3} \mathrm{~N} \cdot \mathrm{s} / \mathrm{m}^{2}$, respectively, as shown in Table 1. In the chloroform-vapor treatment, on the other hand, the elasticity and viscosity were reduced to $1.79 \times 10^{6} \mathrm{~N} / \mathrm{m}^{2}$ and $2.28 \times 10^{3} \mathrm{~N} \cdot \mathrm{s} / \mathrm{m}^{2}$, respectively. This difference suggests the existence of a physical factor other than the loss of turgor pressure in the freezing injury of cell tissue as compared with the chloroform treatment, in which only the plasma membrane was injured because of its mild treatment. In the chloroform-vapor treatment, the only site influenced by chloroform is thought to be the hydrophobic part of the membrane because its $\log P$ value, as an index of hydrophobicity, is 2.0, which is the same value as benzene. The cell wall and intercellular structure, which consists of the hydrophilic components cellulose, hemicelluloses and pectin, is believed not to be affected by the solvent effect of chloroform. In the freezing-thawing, physical and nonspecific injury by the ice crystal formation takes place in cell tissues and changes in the plasma membrane, cell wall, and intercellular structure are expected, so that a larger change in the viscoelasticity was observed than with the chloroform treatment.

Table 1 lists the viscosity and elasticity of carrot and potato samples before and after the two different treatments. In the carrot tissue, the decreases in elasticity and viscosity due to the loss of cell turgor pressure by the chloroform treatment $((\mathrm{A})-(\mathrm{C}))$ were $86.4 \%$ and $68.9 \%$, respectively, in the total decrease by the freezing-thawing $((\mathrm{A})-(\mathrm{B}))$. In the potato cell tissues, the decrease in viscoelasticity due to the loss of cell turgor pressure was more than $90 \%$ in the total decrease. This reflects the difference in the crude fiber contents between carrot and potato (Kagawa, 1998) as shown in Table 1. In our previous paper (Ohnishi et al., 2002), it was reported that crude fiber contents reflect the physical strength of cell wall and intercellular structure, and this strength determines the viscoelasticity of cell tissues after freezing-thawing. Thus, potato, in which the concentration of crude fiber is lower than carrot, was thought to be more influenced by the loss of turgor pressure by the chloroform treatment.

From these findings, we determined the contribution ratio of the loss of turgor pressure and the injury in cell wall and intercellular structure, which are known as major causes of softening by freezing injury, the loss of turgor pressure by plasma membrane injury is believed to be the major cause of softening after freezing-thawing, while the injuries in the cell wall and intercellular structure play an auxiliary role to the change in the rheological properties.

\section{References}

Burke, M.J., Gusta, L.V., Quamme, H.A., Weiser, C.J. and Li, P.H. (1976). Freezing and injury in plants. Ann. Rev. Plant Physiol., 27, 507-528.

Cole, K.S. (1932). Electric phase angle of cell membranes. J. Gen. Physiol., 15, 641-649.

Dejmek, P. and Miyawaki, O. (2002). Relationship between the electrical and rheological properties of potato tuber tissue after various forms of processing. Biosci. Biotechnol. Biochem., 66, 1218-1223.

Drake, B. (1962). Automatic recording of vibrational properties of foodstuffs. J. Food Sci., 27, 182-188.

Ishikawa, E., Bae, S.K., Miyawaki, O., Nakamura, K., Shiinoki, Y. and Ito, K. (1997). Freezing injury of cultured rice cells analyzed by dielectric measurement. J. Ferment. Bioeng., 83, 222-226.

Kagawa, Y. (1998). "Standard Tables of Food Composition in Japan," ed. by Y. Kagawa. Kagawa Nutrition University's Publishing Division, Tokyo, Japan (in Japanese).

Miyawaki, O. and Yano, T. (1980). Physical properties of agricultural products. In "Physical Properties of Food, Vol. 6," ed. by Y. Yamano. Shokuhin Shizai Kenkyu Kai, Tokyo, Japan, pp. 115-129 (in Japanese).

Nishinari, K., Kuji, K., Karaki, Y. and Koide, S. (1977). Transverse vibrations of viscoelastic cylinders. Jpn. J. Appl. Phys., 16, 19-27.

Ohnishi, S., Fujii, T. and Miyawaki, O. (2002). Electrical and rheological analysis of freezing injury of agricultural products. Int. J. Food Propert., 5, 317-332.

Råbergh, C.M.I. and Lipsky, M.M. (1997). Toxicity of chloroform and carbon tetrachloride in primary cultures of rainbow trout hepatocytes. Aquatic Toxicol., 37, 169-182.

Steponkus, P.L. (1984). Role of plasma membrane in freezing injury and cold acclimation. Ann. Rev. Plant Physiol., 35, 543-584.

Sugiyama, J. (1988). Electrical properties of foods for quality evaluation (part 1). Nippon Shokuhin Kogyo Gakkaishi, 35, 647-653 (in Japanese).

Toyoda, K., Kojima, H., Miyomoto, S. and Takeuchi, R. (1997). Measurement and analysis of moisture changes in agricultural products using FFT noise impedance spectroscopy. Drying Technol., 15, 2025-2035.

Virgin, H. (1955). A new method for the determination of the turgor of plant tissues. Physiol. Plant., 8, 954-962.

Webb, M.S., Uemura, M. and Steponkus, P.L. (1994). A comparison of freezing injury in oat and rye: two cereals at the extremes of freezing tolerance. Plant Physiol., 104, 467-478. 